\title{
"Ser um defunto nas mãos do shaykh": sufismo e a produção de masculinidades em uma rede sufi damascena
}

\author{
"Being decesead in shaykh's hands": Sufism and the masculinity productions in a sufi \\ damascene network
}

Resumo: Este artigo objetiva explorar, etnograficamente, idéias e tipos de masculinidades muçulmanas que são construídas a partir da relação entre mestre e discípulo no sufismo, uma das correntes místicas do islã. As questões aqui levantadas podem ser melhor compreendidas como tendo um caráter inicial, exploratório, pois serão analisadas pela primeira vez a partir do enfoque "masculinidade", aqui entendida como uma categoria fluida, que tem uma história e que é contextualmente construída. Espera-se, então, contribuir para o debate sobre o tema, ciente de que a análise que segue demanda mais discussão e aprofundamento. Para tanto, os dados etnográficos aqui analisados são fruto de quatorze meses de trabalho de campo realizado de 2009 a 2010 em Damasco, na Síria, junto aos membros da Kuftariyya, uma importante rede sufi local.

Palavras-chave: sufismo; masculinidades, Síria.

Abstract: This article aims to explore, ethnographically, ideas and types of Muslim masculinities constructed from the relationship between master and disciple in Sufism, one of mystic current of Islam. The issues raised here can be best understood as having an initial character, exploratory, they will be analyzed first from the viewpoint of "masculinity", here taken as a fluid category, which has a history and that is contextually constructed. It is expected to contribute to the debate on the issue, aware that the following analysis requires more discussion and elaboration. To this end, ethnographic data analyzed here are the result of fourteen months of fieldwork from 2009 to 2010 in Damascus, Syria, along with the members of Kuftariyya, an important local Sufi network.

Keywords: Sufism, masculinities, Syria.

\section{Introdução}

Nas últimas décadas, estudos sobre "masculinidades" vêm ganhando maior espaço na literatura acadêmica voltada para a discussão de gênero. Partindo de diferentes questões teóricas, metodológicas e políticas, a discussão contemporânea acerca de "masculinidades" tem apontado para a inadequação de modelos interpretativos que vêem "homem" e "masculinidade" como

\footnotetext{
* Pós-doutoranda no Programa de Pós-Graduação em Antropologia da Universidade Federal Fluminens e e pesquis adora as sociada ao NEOM (Núcleo de Estudos do Oriente Médio/ PPGA/ UFF).
} 
categorias universais, fixas, correspondentes e estáveis. Tais visões, essencialistas de acordo com sua crítica, não consideram os diferentes contextos históricos, sociais e culturais que estão profundamente envolvidos na construção dos diferentes tipos de masculinidade. Neste sentido, "se noções de masculinidade, assim como a própria noção de gênero, são fluidas e situacionais, devemos considerar os vários modos pelos quais as pessoas entendem masculinidade em contextos particulares (...)" (CORNWALL \& LINDISFARNE, 1994, p.03). ${ }^{1}$

À argumentação sobre a diversidade de formas ou estilos em que as masculinidades são contextualmente e historicamente produzidas, juntam-se perspectivas analíticas que ressaltam as múltiplas formas de poder, desigualdades e hierarquias que são elaboradas nos processos de construção de identidades masculinas (CORNWALL \& LINDISFARNE, 1994; CONNELL, 1995; VALE DE ALMEIDA, 1995). Masculinidades, então, estão imersas em complexas dinâmicas e interações entre elementos sociais e individuais, locais e globais, podendo ser entendidas como “(...) configurações de práticas, ou seja, como um conjunto de representações e valores que surgem ou desaparecem ao longo do tempo" (CECCHETTO, 2004, p.72).

Seguindo as assertivas acima, grande parte da literatura acadêmica dedicada aos estudos sobre masculinidades tem orientado a discussão para questões relacionadas às suas interseções e tensões com temas como sexualidade, trabalho, classe, etnia e violência; no intuito de compreender as dinâmicas que estruturam as relações sociais em diferentes contextos culturais e geográficos. No entanto, pouca atenção acadêmica tem sido dada à construção de masculinidades a partir de enfoques religiosos. Como notou Clifford Geertz (1973), sistemas religiosos são capazes de fornecer um modelo de e um modelo para ação, moldando as visões de mundo e de si dos atores sociais.

Dessa forma, o objetivo principal deste artigo é o de explorar, etnograficamente, idéias e tipos de masculinidades muçulmanas que são construídas a partir da relação entre mestre e discípulo no sufismo, uma das correntes místicas do islã. Para tanto, os dados etnográficos aqui analisados são fruto de quatorze meses de trabalho de campo realizado de 2009 a 2010 em Damasco, na Síria, junto aos membros da Kuftariyya, uma importante rede sufi local. As questões aqui levantadas tem ainda um caráter inicial, exploratório, pois serão analisadas pela primeira vez a partir do enfoque "masculinidade". Espera-se, então, contribuir para o debate sobre o tema, ciente de que a análise que segue demanda mais discussão e aprofundamento.

Embora faça parte da realidade religiosa de vários países ocidentais, o islã ainda é ideologicamente considerado como uma tradição religiosa exótica e retrógrada, cujos preceitos são 
vistos como incompatíveis com a chamada "modernidade ocidental" e como uma ameaça à esfera pública secular. Sobretudo no pós 11 de setembro de 2001, a dicotomia "Islã" / "Ocidente" foi fortalecida; delineando, assim como fizeram os Orientalistas do século XIX, uma visão homogênea e essencialista da tradição islâmica e de seus praticantes.

A elaboração política de um suposto "confronto de civilizações" contemporâneo encontrou na "mulher muçulmana" e no seu uso do véu islâmico (hijab) um dos símbolos mais poderosos no processo de confronto entre "nós" e "eles, muçulmanos" (ABU-LUGHOD, 2002; COOKE, 2007). Deste modo, uma expressiva literatura acadêmica, sob diferentes perspectivas teóricas, tem sido produzida sobre construções de feminilidade e a "questão" / "papel" da "mulher" no islã, sobretudo em sociedades majoritariamente muçulmanas, seja no Oriente Médio ou no norte da África, por exemplo. (AHMED, 1992).

Se a mulher muçulmana é, muitas vezes, estereotipada como "submissa" e "oprimida" em algumas análises; por outro lado, homens muçulmanos em geral são associados às estruturas dominantes de poder patriarcal; além de serem, muitas vezes, rotulados e reduzidos a "terroristas" no mundo ocidental pós-11 de setembro. Visões essencialistas do islã também contribuem para leituras que somente percebem os homens muçulmanos através de uma lente que considera a religião islâmica como homogênea e como fonte única de significados para ações masculinas, forjando, então, um homo islamicus. Este, em suas interações econômicas e sociais, sempre colocaria a religião em primeiro plano (SCHIELKE, 2009, p.161).

Poucas produções acadêmicas estão voltadas para o estudo da construção de masculinidades muçulmanas no mundo islâmico mais amplo (OUZGANE, 2006; BARBOSA, 2012). Tais trabalhos, pautando-se em questões já consolidadas no campo de estudos de gênero, chamam atenção para o fato de que as experiências de identidades masculinas não são uniformes e tampouco generalizantes, com diferentes elementos sociais atuando em suas elaborações. Homens e masculinidades muçulmanas, nesta perspectiva, são construídos a partir de contextos históricos e culturais particulares, sendo parte das dinâmicas das relações de gênero que organizam as diferentes sociedades muçulmanas - as quais são amplamente diversificadas internamente e contrastivas externamente. Estas abordagens colocam em xeque a "naturalidade" da visibilidade e da "estabilidade" de uma "identidade masculina" comum a tais sociedades, assim como ressaltam a diversidade de interpretações teológicas islâmicas não apenas sobre as obrigações religiosas de cada muçulmano, homem e mulher, mas também sobre a relação entre eles. Neste aspecto, o sufismo se apresenta como um interessante veículo de análise, uma vez que desde o período medieval, o uso de 
metáforas envolvendo atributos "masculinos" e "femininos" era mobilizado de forma criativa (MALAMUD, 1996) para designar a forte relação entre mestre e discípulo.

\section{Sufismo e a relação mestre-discípulo}

Sufismo (tasawwuf) é a vertente mística do Islã, praticada tanto por muçulmanos sunitas quanto por muçulmanos xïtas. Os muçulmanos que são adeptos do sufismo são comumente chamados de sufis. Neste sentido, não se trata de mais uma divisão sectária da tradição islâmica, mas, sim, de uma corrente de interpretação doutrinal e ritual que é interna ao Islã, sendo definida pela busca de uma experiência direta com Deus. Todavia, o Sufismo se desenvolveu mais no mundo sunita que no xïta. No mundo sunita, por exemplo, as ordens sufis receberam apoio de várias dinastias reinantes. Já no mundo xiita, os shaykhs sufis encontraram oposição do clero xiita e de sua teologia mística (PINTO, 2010, pp.115-116).

Ao longo da história islâmica, diferentes concepções a respeito do que é sufismo e o de que é ser sufi foram elaboradas por seus adeptos. Annemarie Schimmel (1975), por exemplo, chama atenção para as definições dadas por mestres sufis, como Abu al-Qasim al- Junayd (m.910), para quem "Sufismo não é alcançado apenas por orações ou jejuns, mas é a segurança do coração e a generosidade da alma" ou como a definição de Dhu'n-Nun (m.859), para quem "os sufis são pessoas que preferem Deus a tudo, e Deus os prefere a todas as coisas" (SCHIMMEL, 1975, pp.1415). A autora em tela ressalta, ainda, que místicos islâmicos comumente empregam a palavra safa' (pureza) para designar sufismo e a qualidade moral de um sufi ideal. Além disso, sufis também definem sufismo como o caminho do amor, que é Deus.

A história do sufismo está diretamente conectada ao período de formação do Islã como um sistema religioso, bem como ao próprio Profeta Muhammad. De acordo com a tradição islâmica, o Profeta Muhammad era iletrado, e esta condição teria permitido que a exatidão das palavras divinas fosse mantida tal como no momento da revelação corânica. Para as tradições sufis, o fato de o Profeta ser o transmissor das palavras divinas sem qualquer mediação “intelectual", neste caso entendida como o domínio das técnicas de leitura e escrita, garantiu não apenas a perfeição e a pureza da revelação, mas também evidenciou sua dimensão esotérica, a qual teria sido transmitida pelo Profeta aos seus companheiros, de forma direta.

Historicamente, mulheres sufis também são relatadas em hagiografias como detentoras de poder espiritual desde os primeiros tempos do Islã. Fatima, filha do Profeta Muhammad com Khadija, sua primeira esposa, é relatada como a primeira mulher para quem os saberes místicos do 
Islã teriam sido transmitidos. O casamento de Fatima com Ali, primo do Profeta, teria sedimentado o conhecimento esotérico (batini) e orientado sua transmissão. No islã, em linhas gerais, homens e mulheres são entendidos como indivíduos com autonomia moral, embora com diferentes capacidades: a mulher ligada aos cuidados da familia e o homem, ao seu sustento.

De modo geral, pode-se afirmar que a via sufi (tariqa) é entendida como uma jornada mística na qual o muçulmano busca experienciar a realidade divina (haqiqa). Tal jornada é construída a partir de um processo de iniciação no qual o neófito é submetido a diferentes métodos de educação espiritual e a práticas disciplinares, através das quais ele (a) adquire e expressa publicamente, os saberes exotéricos (zahiri) e esotéricos (batini), os quais permitiriam seu avanço no caminho sufi.

Embora ambos saberes sejam importantes nas diferentes tradições sufis, nota-se uma hierarquia entre eles, uma vez que o saber esotérico (batini) é tido como mais completo e profundo do que o saber exotérico (zahiri). Este último pode ser entendido como conquistado através do empenho intelectual, pelo uso de ferramentas cognitivas. Já o primeiro, o saber esotérico, é entendido como aquele alcançado através da experiência mística vivenciada pelo sufi ao longo de sua jornada espiritual, sendo incorporado e mobilizado como parte de sua identidade religiosa. Com isso, o conhecimento religioso ('ilm) dos textos normativos e práticas rituais da tradição islâmica mais ampla é visto pelos sufis como essencial, porém, como superficial e exotérico. De acordo com as concepções de conhecimento elaboradas no Sufismo, somente pelo saber esotérico, o qual desvenda os segredos místicos, é que o sufi chegaria à gnose (márifa).

Desse modo, a hierarquia estabelecida entre os saberes exotérico/esotérico exerce um papel fundamental na classificação dos estágios (maqamat) pelos quais os sufis passam durante o caminho de purificação do self (nafs). Tal hierarquia de saberes também pode ser expressa no processo de construção de autoridades religiosas no sufismo, e, logo, no estabelecimento de relações de poder que daí decorre. O saber esotérico, neste sentido, é adquirido através da iniciação mística sob a supervisão de um shaykh sufi, que, por sua vez, está conectado a uma silsila, isto é, a uma cadeia genealógica de transmissão de conhecimento esotérico cujo primeiro elo é o Profeta Muhammad. É através do Shaykh e de sua baraka que o iniciado (discípulo), percorre a via sufi.

A relação entre um shaykh sufi (mestre - murshid) e seu discípulo (murid) é a base da organização do Sufismo. Nenhum discípulo pode iniciar-se na via mística sem o vínculo com um shaykh. Este é entendido como alguém que já passou por todo o processo de purificação espiritual, atingindo o último estágio do caminho sufi, isto é, a experiência com a verdade/Deus. O shaykh, 
assim, é aquele quem domina o saber esotérico e que pode transmiti-lo, sendo, então, o responsável pelo treinamento espiritual dos seus discípulos com base em sua própria experiência mística. É ele quem ensina ao discípulo a purificar seu self/ego (nafs). Outra qualidade atribuída a um shaykh, segundo os sufis, é sua baraka (graça divina, poder espiritual) que se manifesta de diferentes maneiras, inclusive através de curas.

Aos olhos de seus discípulos, o shaykh é um modelo de perfeição; sua companhia é um benefício, seus gestos, sua fala, seu silêncio, suas atitudes, tudo é entendido por seus discípulos como ensinamento. O shaykh aconselha, reúne os discípulos, conduz rituais, é um guia a quem o discípulo se submete completamente como um "cadáver nas mãos do lavador de corpos" (BÖWERING, 1996, p.140-142).

Um dos principais elementos no processo de iniciação ao Sufismo é a aquisição de adab (regras de comportamento, etiqueta). Segundo Hoffman (1995), a palavra adab pode ser aproximada ao verbo "disciplinar" em árabe ( $a d d a b)$, o que indica que tal etiqueta envolve formas do relacionamento que um sufi deve obrigatoriamente adquirir e mobilizar em sua relação com Deus, com seu shaykh, com os demais discípulos, com a comunidade muçulmana e com os nãomuçulmanos em geral. (HOFFMAN, 1995, p.145). Adab geralmente é complementado pelo termo akhlaq, que pode ser traduzido por moralidade. Enquanto adab é a conduta correta que o sufi deve ter em todas as esferas de sua vida, inclusive, a de não realizar privadamente ações que não faria em público, akhlaq é a avaliação que se faz a respeito das ações individuais dos sufis nos aspectos moral, cognitivo e emocional do self. Adab, neste sentido, pode ser associado à noção definida como habitus por Bourdieu, uma vez que deve ser incorporado pelo sufi como “(...) um conjunto de disposições morais e práticas que guia as suas escolhas e ações” (PINTO, 2005, p.68). Deste modo, adab/akhlaq são requisitos fundamentais a serem adquiridos durante a jornada espiritual, tanto através de estudos textuais da tradição sufi, quanto através de rituais específicos. Passemos, então, às formas como adab/akhlaq eram mobilizados em termos de masculinidades na rede sufi aqui estudada.

\section{Shaykh Ramadan e seus discípulos: a produção de masculinidade religiosa}

Shaykh Ramadan nasceu em 1920, em Damasco. De familia pobre, precisou trabalhar ainda criança, o que o afastou dos estudos. Há várias histórias sobre como ele teria se tornado discípulo de Shaykh Ahmed Kuftaru. Shaykh Kuftaru foi o "Grande Mufti" da Síria por quarenta anos, de 1964 até sua morte em 2004, sendo também o fundador da Kuftariyya, uma das mais importantes redes 
sufis damascenas nas últimas décadas. Na Síria, o sufismo tem um importante papel nas definições locais de islã.

Em uma das histórias sobre Shaykh Ramadan, que me foi contada por Lina — uma professora de inglês, 60 anos de idade e sua discípula há 25 anos - , ele estaria envolvido, na década de 1940, com um movimento de luta armada contra os franceses — que até então ocupavam colonialmente a Síria e que, segundo minha interlocutora, tinham um projeto de "acabar" com o islã no país. Nesse contexto, um dos amigos de Ramadan teria dito a ele que Shaykh Ahmed Kuftaru, então um jovem shaykh que acabara de suceder seu pai como líder religioso na mesquita Abu alNur, era um "mau muçulmano que apoiava os franceses".

Com isso, Ramadan teria ido até a mesquita Abu Nur para confrontar Shaykh Kuftaru. Este, então, teria recebido Ramadan para uma conversa privada, e antes que este the falasse qualquer coisa, Shaykh Kuftaru teria lhe dito tudo o que Ramadan havia planejado fazer com ele. Com isto, o medo que Ramadan sentiu das palavras e do poder de Shaykh Kuftaru foi tão desproporcional, que ele não conseguia se mover para sair da sala do encontro. Depois disso, Ramadan teria pedido ao Shaykh Kuftaru que o guiasse no caminho do islã. Shaykh Kuftaru teria ignorado sua presença, como um teste para purificar suas intenções, segundo observação de Lina. Somente depois desses testes, é que Shaykh Ahmed Kuftaru teria aceitado Shaykh Ramadan como discípulo.

O ponto em comum das narrativas contadas por Lina e demais pessoas ligadas a Kuftariyya é de que Shaykh Ramadan fora uma espécie de "fiel escudeiro" de Shaykh Ahmed Kuftaru, tendo trabalhado como seu motorista e segurança pessoal durante longos anos. Nas narrativas de Lina, shaykh Ramadan teria evitado a morte de shaykh Kuftaru por duas vezes, ao descobrir problemas em seu carro, impedindo que ele o usasse.

O próprio Shaykh Ramadan conta que era analfabeto até os seus 22 anos, momento de vida em que ele teria chegado a Abu al-Nur e começado a freqüentar as aulas públicas de Shaykh Ahmed Kuftaru. Este, na primeira vez em que se dirigiu a Ramadan, perguntou por que ele não anotava seus ensinamentos. Ramadan respondeu que não anotava porque não sabia ler nem escrever, então Kuftaru teria indicado um menino para ensiná-lo. Sobre isso, Shaykh Ramadan comentou em uma de suas aulas públicas na mesquita Abu al-Nur, na qual a autora estava presente "(...) cheguei aqui analfabeto, tenho uma grande gratidão ao nosso shaykh (Shaykhuna) e ao menino que me ensinaram. Hoje, me chamam de especialista religioso ('alim)", referindo-se ao fato de ser líder religioso e ter se graduado em uma das faculdades ( $\left.D a^{\prime} w a\right)$ da Fundação Shaykh Ahmed Kuftaru. 
Shaykh Ramadan não é um especialista religioso sofisticado em suas interpretações corânicas. Apesar de sempre fazer referências a versos do Corão e à hadiths do Profeta Muhammad para basear suas idéias, ele não tem a mesma habilidade com a literatura religiosa como seu irmão, Shaykh Rajeb, o qual se tornou a principal autoridade religiosa na Mesquita Abu al-Nur no período posterior à morte de Shaykh Kuftaru. Shaykh Ramadan raramente é reconhecido como um especialista religioso fora do círculo da Kuftariyya.

Shaykh Ramadan recebeu a função de ensinar mulheres na Abu al-Nur diretamente de Shaykh Kuftaru. Sobre isso, minhas interlocutoras ligadas à Kuftariyya disseram que Shaykh Kuftaru indicou Ramadan para esta tarefa após uma revelação que recebera durante um período em que ficou em reclusão (khalwa) para meditar. Para explicar-me esse tipo de revelação, numa menção implícita aos níveis de conhecimento religioso atribuídos pelo sufismo, uma das minhas interlocutoras, que é discípula de Ramadan, disse que "no Islã não há segredos, é tudo às claras. No entanto, há coisas que precisam de muito conhecimento religioso para se entender. É como uma criança que não pode entender matemática avançada por ser criança, mas que quando crescer, poderá entendê-la”. O poder espiritual (baraka) atribuído a Shaykh Ramadan, e que é a principal fonte que alimenta seu carisma, é, segundo meus informantes, o fato dele conseguir "ver" o que há no coração das pessoas, saber se elas estão bem ou mal intencionadas a respeito de determinadas situações, sendo capaz, inclusive, de adivinhar pensamentos.

Além disso, shaykh Ramadan foi designado por Kuftaru não só para dar aulas para mulheres, isso alguns outros shaykhs também fazem, mas para lidar com questões que as envolvem diretamente em seu dia-a-dia e para iniciar mulheres no Sufismo. Poucos são os shaykhs que aceitam mulheres como discípulas diretas. Era comum shaykh Ramadan ser procurado em seu apartamento, localizado no quarto andar da Fundação Shaykh Ahmed Kuftaru, tanto por suas discípulas quanto por mulheres da Kuftariyya que não faziam parte de sua rede (ou, ainda, por muçulmanas não-sufis e até por mulheres cristãs) para aconselhamentos ou pedidos, como por exemplo, para mediar problemas em casamentos, para dar conselhos a respeito de determinadas contendas familiares, ou até mesmo para tratar alguns problemas de saúde.

No dia em que conheci Shaykh Ramadan, por exemplo, cheguei ao seu apartamento com uma de minhas amigas ligada à Kuftariyya, mas que não era sua discípula. $\mathrm{O}$ motivo da visita ao Shaykh, segundo minha amiga, era o de que o filho de sua sobrinha, um menino com quatro anos de idade, que falava com fluência, começou a gaguejar repentinamente. Sua sobrinha, que nos acompanhava juntamente com o menino, me disse que ela precisou viajar por uns dias e, por isso, 
deixou o menino sob cuidados dos tios paternos. Depois desse dia, segundo ela, o menino teria apresentado os problemas na fala. Quando Shaykh Ramadan nos atendeu em sua sala, elas contaram essa história para ele. Shaykh Ramadan, então, levantou-se e colocou suas mãos sobre a cabeça do menino, dizendo "em nome de Deus" seguido de alguns versos corânicos. A criança sorria para a mãe, enquanto o Shaykh pronunciava as fórmulas rituais. Semanas depois, encontrei a mãe do menino e perguntei por ele. Ela disse que sua fala estava melhor, embora não totalmente fluente.

Shaykh Ramadan também é conhecido por suas indicações fitoterapêuticas, receitando combinações de ervas medicinais, de chás ou certos tipos de alimentos para quem o procura com algum mal físico. Tem livros especificamente sobre isso, que segundo ele, foram escritos seguindo as recomendações do Profeta Muhammad a respeito das práticas alimentares e do poder da alimentação saudável. Para um de seus discípulos, por exemplo, que se queixava de problemas digestivos, Shaykh Ramadan recomendou-lhe uma dieta a base de chá. Inclusive, o seu dia-a-dia é marcado por essas questões: é ele quem prepara a comida em sua casa, ou quando não faz, sempre supervisiona as cozinheiras. A maior parte dos alimentos que consome é produzida em seu sítio. Em várias de suas aulas, Shaykh Ramadan repreendeu mulheres que só cozinham "lixo" para sua familia, como sanduíches e batatas-fritas. Tal postura de Shaykh Ramadan está fortemente conectada com seu modo de treinar espiritualmente seus discípulos.

A longevidade e a disposição física de Shaykh Ramadan corporificam seus ensinamentos e são "provas" aos olhos dos seus seguidores de seu poder espiritual: aos 90 anos de idade, ele profere aulas públicas para as mulheres no sábado à tarde, e, à noite, para os homens. Também profere aulas às quartas-feiras à noite só para seus discípulos e discípulas. Além disso, Shaykh Ramadan lidera o dhikr (ritual de invocação mística dos nomes de Deus) na mesquita Abu al-Nur todos os dias antes do nascer do sol, atende às pessoas diariamente no seu apartamento/ escritório na Abu alNur e, à noite, ao retornar para sua casa (um sítio afastado do centro da cidade), dirige seu carro no trânsito extremamente conturbado de Damasco.

As aulas privadas de Shaykh Ramadan com seus discípulos também acontecem na mesquita Abu al-Nur. Muitas de suas discípulas são casadas com seus discípulos — o próprio Shaykh Ramadan atua nessa área de arranjos matrimoniais internos à sua rede. Assim, não só sua rede de discípulos e, logo, de influência e poder, se amplia, bem como ele evita alguns problemas como os ciúmes de maridos da relação entre suas mulheres e o shaykh. A prática de casamentos internos às redes que compõem a Kuftariyya é bastante comum. A rede sufi comandada por shaykh Ramadan é composta por centenas de discípulos, entre homens e mulheres. 
Um discípulo francês de Shaykh Ramadan que o visitava pela segunda vez na mesquita Abu al-Nur, em Damasco, disse para mim e para uma discípula síria do referido shaykh que estava impressionado pelo fato de mulheres e homens transitarem livremente pelos cômodos do apartamento de Ramadan, diluindo as fronteiras entre gêneros que eram estritamente observadas no cotidiano da Fundação Shaykh Ahmed Kuftaru, braço institucional da Kuftariyya, que reúne diversos cursos. A discípula do shaykh respondeu que a presença conjunta de homens e mulheres não era proibida (haram) naquele contexto porque, segundo ela, Shaykh Ramadan "conhecia o coração de todos os que freqüentavam sua casa" e "que havia mulheres que preferiam não se misturar, mas eu não me importo, pois tudo depende da intenção que há no coração das pessoas”. Neste exemplo etnográfico, a idéia da intimidade cultural criada entre os discípulos e do poder da espiritualidade do Shaykh foi acionada na explicação de sua discípula para a diluição temporária de determinadas interpretações islâmicas que são localmente aplicadas como a separação entre homens e mulheres. A "pureza espiritual" de Shaykh Ramadan, neste sentido, seria distribuída para o ambiente e para os modos pelos quais seus discípulos poderiam dividir o mesmo espaço físico, por exemplo, o que aponta para as diferentes maneiras que os aspectos normativos da tradição islâmica em relação às questões de gênero são localmente elaborados.

De fato, a movimentação diária de discípulos homens e mulheres no apartamento de Shaykh Ramadan, sobretudo nas quartas, sextas e sábados era bem intensa. Todavia, em suas aulas privadas com os discípulos, por falta de espaço no pequeno apartamento, as divisões de gênero eram observadas. Os homens iam com o shaykh para outra sala localizada no interior da Fundação Shaykh Ahmed Kuftaru e as mulheres permaneciam no apartamento. Assim, as mulheres ouviam os ensinamentos do Shaykh através de caixas de som que eram espalhadas pelo apartamento. Já nas sextas e sábados, por exemplo, os discípulos do shaykh que ficavam em seu apartamento podiam ouvir e assistir tanto as aulas de Ramadan quanto o sermão de sexta-feira através de aparelhos de TVs que havia nos quartos e na sala.

Para os discípulos, pertencer a uma rede religiosa, além de benefícios espirituais, também pode trazer alguns benefícios de ordem econômica ou social. Era comum, por exemplo, que alguns discípulos ligados ao ramo do comércio fornecessem descontos em produtos para seus "irmãos" também vinculados à mesma rede. Por duas vezes, por exemplo, eu mesma obtive descontos: acompanhei uma das minhas amigas pertencentes à rede de Shaykh Ramadan até duas lojas que pertenciam a discípulos do mesmo shaykh. Chegando às lojas, após cumprimentar os donos, falarem sobre Shaykh Ramadan, ela comprou os produtos que desejava. Também comprei alguns. Na hora 
do pagamento, ela obteve seus descontos e me apresentou aos donos, dizendo que eu era brasileira e que estava assistindo às aulas de Ramadan, pelo que obtive descontos também. Este exemplo mostra como circuitos morais são estabelecidos a partir destes vínculos de pertencimentos religiosos. Assim, uma rede de trocas e de favores é criada em paralelo com a rede religiosa, que pode ser lida também como uma estratégia de sobrevivência em uma situação economicamente difícil como a da Síria, sobretudo após reformas governamentais que implicaram em cortes de subsídios alimentares.

Uma das minhas interlocutoras, que não freqüentava as aulas e a rede de Ramadan, disse-me que Shaykh Ramadan era uma espécie de "pop star" entre as mulheres, não porque ele queria, mas porque algumas delas, usando sua expressão, ficavam "malucas" (majnunas) com sua presença. De acordo com suas palavras, Shaykh Ramadan era um homem "puro de coração, que ficava $24 \mathrm{~h}$ conectado com Deus, e que, por isso, ninguém nunca havia visto uma ação errada feita por ele". De fato, Shaykh Ramadan era fonte de um carisma impressionante, sobretudo, junto ao público feminino. Embora as mulheres não o tocassem enquanto ele passava, elas olhavam emocionadas para ele, algumas com olhos lacrimejantes; outras tiravam fotos com celulares, falavam "assalam aleikum" (que a paz esteja com você), ou, ainda, levantavam as mãos em sua direção. Seu carisma era oriundo principalmente do poder espiritual (baraka) que suas discípulas, e também todas as minhas interlocutoras, atribuíam a ele. Fida, por exemplo, uma jovem estudante de 18 anos, tinha uma foto de Shaykh Ramadan como papel de parede em seu celular. Quando vi a foto, ela logo me explicou que era "bom para sua mente e para seu coração tê-lo sempre perto", evocando, com isso, a noção sufi de "presença" (hadra), que pode indicar tanto a presença do Shaykh quanto a do Profeta Muhammad.

A relação com os homens ligados à sua rede também se dava nestes termos: quando Shaykh Ramadan chegava ou saía da mesquita, seus discípulos caminhavam em sua direção, no intuito de tocá-lo e de beijar sua mão. Uma intensa atmosfera emocional tomava conta do ambiente. Seus discípulos baixavam os olhos e só lhe dirigiam a palavra quando fossem solicitados ou quando o procuravam para resolver problemas particulares. Estavam sempre prontos a atender os chamados do Shaykh e o temor e respeito que tinham em sua presença era tanto que todos se levantavam em sua presença e não sentavam ou se retiravam sem sua permissão.

O estilo de vestimenta e de oratória de Shaykh Ramadan era bastante singular se comparado com o de outros Shaykhs que também proferiam aulas públicas na mesquita Abu al-Nur. Diferente destes, Ramadan não usava abaya (um tipo de vestimenta usada por pregadores muçulmanos) e 
também não usava 'amaqa (um chapéu branco usado pelos shaykhs), mas apenas uma taqiya (touca) e uma camisa e calça brancas. O tom de sua oratória nas aulas públicas que proferia era firme, às vezes esbravejava, às vezes provocava risos na audiência ao narrar alguns acontecimentos ou histórias. Os eixos temáticos que eram abordados nessas aulas giravam em torno de questões objetivas, em como aplicar os preceitos islâmicos nas arenas práticas da vida cotidiana, por exemplo. Além disso, os ensinamentos de Shaykh Ramadan no contexto das aulas também se constituíam em arenas discursivas de produção e circulação de concepções e práticas a respeito do que era localmente entendido como o "papel da mulher" e o "papel do homem" na sociedade e no Islã.

Através de histórias de seus discípulos ou das demais pessoas que o procuravam para solicitar conselhos a respeito de problemas entre pais e filhos, Shaykh Ramadan construía modelos idealizados do que seria uma "boa mulher", "um bom marido", "uma boa mãe" e "um bom pai" a partir dos preceitos religiosos. Dessa forma, a casa, o marido e os filhos podem ser interpretados como uma extensão moral da mulher, uma vez que como mãe e esposa, a mulher muçulmana não só é portadora da honra da familia, como também simboliza a sua estabilidade. Assim, a mulher verdadeiramente devota, é aquela que tem autocontrole, e o transmite para o universo doméstico.

Articulações entre modelos de e modelos para ação femininas e masculinas pautados em obrigações religiosas, tais como elaboradas por Shaykh Ramadan, estão diretamente relacionadas às construções culturais mais amplas da sociedade local a respeito de identidades de gênero. No entanto, embora no modelo nativo a respeito de identidades e atribuições de gênero haja uma construção do feminino ligado ao espaço doméstico e do masculino ao espaço público, é preciso ressaltar que surgem esferas intermediárias de atuação das mulheres no espaço público e de homens no espaço doméstico, a partir de interpretações locais a respeito das obrigações religiosas de homens e mulheres buscarem conhecimento religioso e de o colocarem em prática.

Em linhas gerais, os ensinamentos de Shaykh Ramadan se organizavam em torno da concepção islâmica que divide o ser humano em três dimensões existenciais: o corpo (jism), o self (nafs) e a alma (ruh). Sua abordagem concentrava-se principalmente nas duas primeiras dimensões, que eram interpretadas de acordo com concepções sufis promovidas na Kuftariyya. O corpo e o self eram mobilizados nos ensinamentos de Shaykh Ramadan como arenas complementares através das quais os conhecimentos esotéricos (batini) e exotéricos (zahiri) da tradição islâmica se manifestavam. Os seguintes trechos dos seus ensinamentos podem contribuir para uma melhor percepção a respeito dessas questões: 
Hoje falarei da criação. Deus criou o homem e a mulher. Deus nos cria a partir do óvulo e do esperma. Deus nos diz no Alcorão sagrado que nos deu tudo que precisamos. Mas o homem é a criatura mais desacreditada e ingrata que existe (...) O homem quando tem uma dor se sente muito vulnerável. Eu aconselho vocês a cuidarem primeiro do interior e depois do exterior. O coração precisa de comida e bebida? Onde podemos comprar comida para o coração? Se você está conectado com Deus terá esses nutrientes. O Profeta Muhammad, que a paz e as bênçãos de Deus estejam sobre ele, disse que lembrar-se de Deus (dhikr Allah) é o alimento para o coração, enquanto comida é alimento para o corpo. Por favor, cuidem do corpo e do coração, nutram ambos.

O corpo, neste sentido, era interpretado como uma "máquina perfeita criada por Deus", mas que os seres humanos não reconheciam tal "dádiva". A relação feita entre "comida para o corpo" e "comida para alma" pode ser entendida a partir das concepções de conhecimento exotérico e conhecimento esotérico que focalizam no corpo como a principal arena em que tais saberes são visivelmente inscritos.

Autocontrole, de acordo com interpretações esotéricas do sufismo, é uma noção investida de concepções a respeito do treinamento espiritual a que um discípulo é submetido no processo de aniquilação do nafs ammara, que corresponde ao primeiro estágio do caminho sufi. Este nafs é entendido como sendo o tipo mais "mundano", isto é, que está relacionado aos desejos e paixões humanas e, portanto, responsável por levar os seres humanos a desobedecerem aos desígnios de Deus. Assim, o controle e a aniquilação desse nafs se dá nos aspectos mais simples da vida cotidiana, tal como a alimentação.

A prática do dhikr (recordação dos nomes de Deus) e a oração da alvorada (fajr) também eram pontos centrais dos ensinamentos e das recomendações de Shaykh Ramadan. Ele sempre ressaltava que só através do $d h i k r$ se poderia atingir Deus. Segundo narrativas do próprio shaykh Ramadan, ele conseguia se comunicar espiritualmente com Shaykh Kuftaru, na época em que este ainda vivia, sem que os dois estivessem presentes no mesmo lugar. Ramadan dava esse exemplo durante suas aulas principalmente para enfatizar a conexão espiritual forte que havia entre ele, como discípulo, e Shaykh Kuftaru, como mestre. Em uma das histórias, Shaykh Kuftaru estava fazendo peregrinação em Meca e Shaykh Ramadan estava na mesquita Abu al-Nur. Ramadan teria se conectado espiritualmente com Kuftaru e conseguido ouvir palavra por palavra das preces feitas pelo último. Em seguida, teria comentado com algumas pessoas, e assim que Shaykh Kuftaru retornou, Shaykh Ramadan teria repetido as palavras ditas por ele em Meca, as quais Shaykh Kuftaru teria confirmado sua veracidade. 
Dessa forma, a idéia de conexão com o shaykh tal como expressa por Ramadan só era possível via prática de dhikr. Ele aconselhava aos seus discípulos a fazer esse ritual ao menos quinze minutos por dia, após a oração da alvorada. Dizia que só lembrando Deus é que alguém poderia se tornar um crente verdadeiro. No sufismo, um discípulo se conecta a Deus via $d h i k r$ através da ajuda de seu shaykh. Este é quem tem os conhecimentos necessários para se chegar à verdade divina. Essa era a fonte de sua autoridade moral e carismática perante seus discípulos. Em uma das aulas, Shaykh Ramadan ressaltou a importância da relação mestre/discípulo da seguinte forma:

Se você está comprometido com o Corão e com o que Deus ordenou, se está conectado a um Shaykh e lembra Deus (Dhikr Allah) sempre, você terá ótimos resultados. É como colocar a mão no forno e não se queimar. É preciso não gastar tempo assistindo TV. Tenho uma rotina diária de acordar às 3h00, leio o Corão até a hora da oração da alvorada (fajr), depois faço dhikr. Tomo meu desjejum e volto para cama às $9 \mathrm{~h} 00$. Depois me levanto às $11 \mathrm{~h} 00$ e começo minhas atividades diárias. As aulas te ajudam durante a semana, mas ainda assim é preciso lembrar de Deus todos os dias, não achem que freqüentar a mesquita é o suficiente.

De acordo com Shaykh Ramadan, vencer os desejos do nafs só era possível a partir do comprometimento com a religião. A idéia de comprometimento era elaborada em seu discurso a partir das interseções entre o interior e o exterior, através de entendimentos esotéricos e exotéricos. Comprometer-se implicava em mudança de comportamento, através da criação de um habitus devoto. Para tanto, práticas disciplinares (ASAD, 1993), como dhikr, orações e leituras do Alcorão, seriam fundamentais no processo de construção de subjetividades religiosas orientadas pelo sufismo.

Assim, questões envolvendo masculinidades são trazidas para o centro da discussão. $\mathrm{Na}$ Síria, como em outras realidades culturais, há diferentes modelos de masculinidades que circulam e que são apropriados na vida prática dos homens. No caso do sufismo e nas relações entre mestre e discípulo, como no caso da rede sufi organizada a partir de Shaykh Ramadan, idéias sobre masculinidade são elaboradas de formas criativas, no sentido que apontam para a criação de estilos de masculinidade que ora se contrapõe e ora se combinam com versões de masculinidades dominantes, do homem como provedor e chefe de família, "senhor de si”, para usar a expressão de Vale de Almeida (1995).

Um dos discípulos de Shaykh Ramadan, um comerciante em seus quarenta anos, me relatou que Shaykh Ramadan era um pai espiritual, que o guiava em tudo, que o tinha criado 
espiritualmente. Já outro discípulo me disse que amava Shaykh Ramadan e que era pelas suas mãos que ele se tornara um "homem de verdade", segundo as prescrições islâmicas, uma vez que muitos sufis que conheci em Damasco me relataram sua iniciação mística como uma passagem metafórica da morte para vida. Daí a idéia do neófito ser um "defunto" nas mãos do seu "lavador", isto é, de seu shaykh. Assim, nos discursos de Shaykh Ramadan em suas aulas públicas podem ser encontradas várias referências sobre o compromisso do discípulo para com o shaykh e da dependência daquele em relação ao mestre espiritual. $O$ discípulo deve servir ao seu mestre com humildade, modéstia e total submissão, pois acredita-se que essa é uma forma de aprender a controlar os impulsos e desejos do nafs e de aproximar-se de Deus, uma vez que shaykhs sufis são considerados como "amigos de Deus".

Shaykhs sufis devem ser obedecidos em todas as instâncias, e a força de sua interferência na vida do seu discípulo é tamanha, que o discípulo é visto como uma criança, que precisa ser educada por seu "pai" espiritual. Todavia, como ressaltou Malamud (1996), desde o período medieval, textos de teólogos sufis fazem referência a imagens maternais simbolizando a ligação entre shaykhs sufis e seus discípulos. Neste sentido, mestres sufis são metaforicamente comparados a mães que nutrem seus filhos espirituais, que os amamentam, e que garantem à vida aos seus bebês. Já os discípulos, como crianças, são alimentados espiritualmente e, deste modo, são dependentes do shaykh, numa analogia que os lembram de sua dependência de Deus (MALAMUD, 1996, p.97).

Deste modo, no caso dos ensinamentos e da relação entre Shaykh Ramadan e seus discípulos, ao mesmo tempo em que discursos sobre modelos de masculinidades dominantes como o "papel" do homem muçulmano na criação, proteção e na manutenção material da família são enfatizados e reforçados; por outro lado, idéias que ressaltam a dependência e subordinação espiritual e emocional entre homens a partir da relação mestre e discípulo no sufismo são tidas como essenciais na construção das identidades e subjetividades de muçulmanos sufis.

\section{Conclusão}

Este artigo procurou levantar algumas questões a respeito de idéias e tipos de masculinidades religiosas que são construídas através da análise das relações entre mestre e discípulo no sufismo. Para tanto, destacamos as relações entre Shaykh Ramadan e seus discípulos, e as formas dinâmicas nas quais atributos localmente identificados como "masculinos" como "controle de si', "autonomia" e "independência" são criativamente reelaborados através da iniciação mística de homens muçulmanos no sufismo. 
A autoridade religiosa de Shaykh Ramadan, neste sentido, pode ser localizada na força de seu carisma pessoal e na sua capacidade de atrair seguidores por conta de sua reputação como um Shaykh "puro de coração", "extremamente devoto", "conectado com Deus, vemos isso em seus olhos" etc., expressões localmente utilizadas para classificá-lo como um Shaykh autêntico, condizente com as concepções do papel de uma autoridade religiosa sufi tal como as elaboradas pela Kuftariyya. Nesta perspectiva, shaykh Ramadan corporifica ao menos metaforicamente diferentes atributos masculinos e femininos em sua relação com seus discípulos: ele é o pai, a quem os discípulos temem por seu poder espiritual e a quem devem total submissão e, ao mesmo tempo, é a mãe, que nutre, ama e cuida espiritualmente de seus discípulos. Assim, a hierarquia e dependência espiritual entre homens, a partir da relação Shaykh e discípulos, é legitimada a partir de entendimentos que a percebem como o próprio tipo de relação estabelecida entre Deus e os homens.

Já os discípulos, em suas posições de subordinação e dependência em relação ao Shaykh, ao mesmo tempo que são vistos como crianças que precisam dos cuidados de outro homem, estando em suas mãos como "defuntos", são impulsionados a agirem conforme os códigos islâmicos normativos que prescreve os "papéis sociais" que os homens muçulmanos devem assumir nas arenas da vida cotidiana, como "chefes de família". Se, em alguns momentos, a posição de submissão a um outro homem pode ser vista como uma forma de "emasculação", de acordo com os modelos de masculinidade que circulam localmente, é através desta dependência a um outro homem, o shaykh, que os discípulos sentem sua transformação em "homem de verdade", conforme me disse um discípulo de shaykh Ramadan.

Deste modo, este artigo não pretendeu fazer uma revisão teórica sobre gênero e masculinidades, mas, sim, fornecer dados empíricos de uma realidade cultural em que as interpretações religiosas, como o Sufismo no islã, contribuem para tornar o debate ainda mais complexo. Embora visões essencialistas do islã enquadrem os muçulmanos numa moldura estática, em que suas masculinidades são percebidas como homogêneas e a-históricas, este artigo procurou mostrar que no islã há diferentes formas de construção de subjetividades religiosas, em que as noções de masculinidades são fluidas e dinâmicas, devendo ser contextualmente analisadas.

\section{Referências bibliográficas}

ABU-LUGHOD, Lila. Remaking women. Feminism and Modernity in the Middle East. Princeton: Princeton University Press, 1996. 
. Do Muslim women really need saving? Anthropological Reflections on Cultural Relativism and its others. American Anthropologist, v.104,n.3,p.783-790, 2002.

AHMED, Leila. Women and gender in Islam: Historical roots of a modern debate. Yale: Yale University Press, 1992.

ASAD, Talal. The Idea of an Anthropology of Islam. Washington: Georgetown University, 1986.

. Genealogies of Religion: Discipline and Reasons of Power in Islam and Christianity.

Baltimore: John Hopkins University Press, 1993.

BARBOSA, Gustavo. Brigas de galo pelo avesso: Fazendo "sexo" e desfazendo "gênero" em Chatila, Líbano. Revista de Antropologia . v. 54, n. 2; 'Dossiê Pensar com Pierre Clastres" (no prelo).

BÖWERING, Gerhard. Règles et rituels soufis. In: POPOVIC, A. \& VEINSTEIN, G. Les Voies d' Allah. Paris: Fayard, 1996.

CECCHETTO, F R. Violência e estilos de masculinidade. Rio de Janeiro: editora FGV, 2004.

CHAGAS, Gisele Fonseca. Sufismo, carisma e moralidade: uma etnografia do ramo feminino da tariqa Naqshbandiyya-Kuftariyya em Damasco, Síria. Tese de Doutorado em Antropologia/ UFF, 2011.

- Muslim Women and the Work of da'wa: The Female Branch of the tariqa Naqshbandiyya-Kuftariyya in Damascus, Syria. Middle East Critique, v. 20, p. 207-218, 2011.

CONNELL, Robert. Masculinities. 1. ed. Sydney: Allen \& Unwin, 1995.

COOKE, Miriam. The Muslimwoman. Cont Islam, n.1, p.139-154, 2007

CORNWALL, Andrea; LINDISFARNE, Nancy (eds.). Dislocating Masculinity: Comparative Ethnographies. 1. ed. London: Routledge, 1994.

GEERTZ, C. The interpretation of cultures: selected essays, New York, Basic Books, 1993.

HOFFMAN, Valerie. Sufism, Mystics and Saints in Modern Egypt. Columbia: University of South Carolina Press, 1995.

MALAMUD, Margaret. Gender and Spiritual Self-Fashioning. The Master-Disciple Relationship in Classical Sufism. Journal of the American Academy of Religion. v.64, n.1, pp.89-117, Spring 1996.

PINTO, Paulo Gabriel H. da R. Sufismo, Performance Moral e Poder na Síria Contemporânea. Tiraz: Revista de Estudos Árabes e das Culturas do Oriente Médio, n.2,p.51-73. SP: USP, 2005. . Islã: religião e civilização. Uma abordagem antropológica. SP: Editora Santuário, 2010. 
SCHIMMEL, Annemarie. Mystical Dimensions of Islam. Chapel Hill: The University of North Carolina Press, 1975.

VALE DE ALMEIDA, Miguel. Senhores de Si. Uma Interpretação Antropológica da Masculinidade. Lisboa: Fim de Século, 1995.

\section{Notas}

\footnotetext{
${ }^{1}$ No original: "If notions of masculinity, like the notion of gender itself, are fluid and situational, we must consider the various ways people understand masculinity in any particular setting". (CORNWALL \& LINDISFARNE, 1994, p.03).
}

Recebido em maio de 2012.

Aprovado em junho de 2012. 